\title{
The effect of educational program based on beliefs, subjective norms and perceived behavior control on doing pap-smear test in sample of Iranian women
}

\author{
Ali Khani Jeihooni ${ }^{*} \mathbb{0}$, Hanieh Jormand ${ }^{2}$ and Pooyan Afzali Harsini ${ }^{3}$
}

\begin{abstract}
Objective: Cervical cancer is considered treatable as long as it is detected early and managed effectively. Pap smear test is a screening tool that plays an important role in the early detection, prevention and can prevent any early cervical cell changes from becoming cancer. This study aims to survey the effect of educational programs based on beliefs, subjective norms, and perceived behavior control on doing the pap-smear test in a sample of Iranian women.

Materials and methods: This experimental interventional study was performed on 300 women admitted to Fasa City, Fars Province, Iran health centers in 2018-2019. A questionnaire consisting of demographic information, knowledge, Health Belief Model, and Theory of Planned Behavior constructs were used to measure on doing of Pap smear test in women before and after 6 months' educational intervention.

Results: The results revealed that 6 months after the intervention, 108 women (72\%) in the experimental group and only 9 women (6\%) in the control group received the Pap smear test.

Conclusions: The current research results revealed that education based on the combination of the health Belief model and theory of planned behavior might be promoting participation and an increasing rate of receiving Pap smear tests in women.
\end{abstract}

Keywords: HBM model, Behavior control, Iranian women, Pap-smear, Theory of planned behaviour (TPB)

\section{Introduction}

Cervical cancer is the sixth most common cancer and is the second principal reason for cancer morbidity in women [1]. Nearly $1.6 \%$ of deaths are caused by cancer in women and $15 \%$ of deaths are caused by gynecologic cancer [2] so that 440,000 new cases of cervical cancer are reported annually and nearly $80 \%$ of them occur in underdeveloped and developing countries [1]. The global

\section{*Correspondence: khani_1512@yahoo.com}

${ }^{1}$ Nutrition Research Center, Department of Public Health, School

of Health, Shiraz University of Medical Sciences, Shiraz, Iran

Full list of author information is available at the end of the article prevalence of cervical cancer is estimated to be $11.7 \%$, with its highest prevalence has been reported in the African continent (24\%), Eastern Europe (21.4\%), and Latin America (16.1\%) [1]. Evidence suggests that an increasing number of people are affected by this disease at a global level, especially in Iran [3]. Cervical cancer is the third most common cancer in Iran. Based on the national report of cancer cases registry, the rate of cervical cancer among Iranian women in different provinces has been reported to be $7.1 \%$. Studies suggest that nearly $10 \%$ of all invasive cancers in women occur in the uterus, $30 \%$ of them occur in the cervix [4]. Nearly one million women are affected by advanced cervical cancer annually, which 
more than $50 \%$ of them die, as globally cervical cancer kills approximately 300,000 women and affects nearly 600,000 women yearly, particularly middle-aged women and those living in lower-resource settings [5]. Cervical invasive cancer is considered preventable cancer through HPV vaccination only which is treatable as long as it is detected early and managed effectively [6], and its 5-year survival rate in the pre-invasive stage is nearly 100\% [7]. Doing a regular screening program in this pre-invasive period is highly valuable and can save an individual from the terrible nightmare of cancer [8-10]. Moreover, some studies have reported several causes for cervical cancer, including prolonged uses of oral contraceptive pills, low age at first sexual intercourse, low age at first birth, great number of sexual partners during life, high pregnancy rates, high parity, smoking, illiteracy, low literacy, low economic and social status, among others [11]. Pap smear test is a simple, cost-effective, and uncomplicated method, preferred for screening of cervical cancer $[8,12$, 13]. Evidence in several countries suggests that screening programs can reduce cervical cancer mortality rates by up to $60 \%$ [14]. However, a large number of women do not, unfortunately, receive a Pap smear test for different reasons, which the most important of them is the fear of having cervical cancer, the painful nature of this test, and shame of doing it, inadequate education, cultural problems, false understandings of the disease, and other psychosocial causes or demographic characteristics $[15,16]$. However, screening is an important secondary prevention strategy as cervical cancer is treatable as long as it is detected early [17]. Studies suggest that the rate of Iranian women, who received this test at least once, approximately $28-30 \%$, which is estimated at a low rate $[18,19]$. The recommendation on the time of starting for screening and its duration varies in various countries, and there are still controversial views on this issue, depending on the prevalence of the disease in different countries and the cost-effectiveness of the screening method [20]. Based on the Ministry of Health and Medical Education Policies in Iran, the Pap smear test is done in health centers, for women at age group of 20-65 years once per year, and if the result is negative, once per 3 years, based on the conditions specified in the national guidelines [21]. Providing education on promote participation and increasing the rate of receiving Pap smear test is one of the most effective actions taken for early diagnosis of uterine cancer [22]. Though cervical cancer is highly preventable by screening while, hopefully most of cervical invasive cancers are diagnosed in women, who have not received the Pap smear test [16].

As it is mentioned, the rate of receiving Pap smear test in a large number of Iranian women is low, in this regard, the evidence demonstrated intervention education and promotion programs with targeting the developing and promoting motivation factors, could help to promote participation and increasing the rate of receiving Pap smear test in women [9]. The effects of educational interventions greatly depend on using the appropriate models during the selection of educational programs and health problems [23]. Selecting an appropriate health education model or theory is considered as the first step in the planning process of an educational program, and effective health education depends on skill in the use of the appropriate theories and strategies. In this regard, the Health Belief Model (HBM) emphasizes the point that how individual Beliefs and perceptions of the fear of health problems and the assessment of the benefits and barriers of preventive behavior lead to the adoption of behavior [23, 24]. According to this model, one should believe that she is susceptible to a disease such as cervical cancer (perceived susceptibility), women should understand the level of this risk and the seriousness of its various complications in her life (perceived severity) and consider the suggested behaviors such as Pap smear is useful in reducing the risk or severity of her disease (perceived benefits) so that women can overcome the inhibiting factors such as negative emotions, lack of time, etc. (perceived barriers) $[25,26]$. Results of Iranian contextualized confirmed that focusing on the perceived benefit and barrier variables of the Health belief model could promoting adherence in pap smear testing in women, also, the perceived benefit and barrier variables have been considered strong predictors of regular pap smear testing among them [27, 28]. Another theory of health education is Theory of Planned Behavior (TPB), based on this theory the best predictor of behavior is one's intention to be involved in behavior, this key variable is predicted by two variables of behavior-related attitude (general or positive negative evaluation of behavior) and subjective norms (general perception of social pressure to do) [24]. The success of this theory in explaining the behavior depends on the level to which behavior is voluntarily controlled. People often act based on their perception and perception of what others think they should do, and their intention to accept behavior is potentially affected by people who have a close relationship with them. In this theory, one's subjective norm is the result of multiplying normative beliefs in the motivation to follow the targeted behavior despite these expectations. Additionally, perceived behavior control is defined as the one's feeling that how much doing or non-doing a behavior is voluntarily controlled [23, 29].

Given conducting previous cross-sectional studies on the target population and the role of people perceptions and beliefs in doing the Pap smear test, the importance of effective subjective norms such as a partner, physicians, 
and friends, and people perceived behavior control to encourage and empower them on doing Pap smear test $[26,30]$. So, the current research was carried out to evaluate the effect of educational intervention based on the combination of the health Belief model and theory of planned behavior on doing of Pap smear test in women.

\section{Materials and methods}

The current research is an experimental interventional and prospective study, carried out on 300 women admitted to Fasa health centers in 2018-2019. Out of 6 urban health centers in Fasa City, 2 centers were randomly selected. Individuals were selected based on the household medical file number and were invited to participate in the research. After selecting the individuals, they were randomly assigned into either the experimental or control group (each group containing 150 subjects). After explaining the research objectives for participants and obtaining informed consent and ensuring the confidentiality of all information, a pre-test questionnaire was completed by two groups. Inclusion criteria: Non-pregnant married women who have had passed at least 6 months of their marriage and without any history of cancer and hysterectomy. Exclusion criteria: non-willingness and informed consent of the women to participate in the research and absence of more than 2 sessions in the educational program. It is essential to be mentioned women in the experimental group received extensive education on cervical cancer and Pap-smear testing, while women in the control group received no educational intervention.

The sample size was calculated 150 women in the experimental group and 150 women in the control group after conducting a pilot study. The pilot study was conducted on 40 women who met the inclusion criteria and were selected randomly by using the sample size formula and considering the $(P<0.05)$, the confidence level of 95\%, and correlation coefficient of 0.37 and considering the drop out of $10 \%$.

$$
n=\left(\frac{\left(Z_{1-} \alpha_{/ 2}+Z_{1-\beta}\right)}{0.5 \times \ln \left(\frac{1+r}{1-r}\right)}\right)^{2}+3
$$

The data collection tool in this research was based on other studies $[26,30]$. The first part included demographic information of subjects, including age, number of children, age at the first pregnancy, history of receiving the Pap smear, job, education level, being postmenopausal, and the history of cervical cancer in the family.

The second part included questions on the health Belief model and the theory of planned behavior which are design base on theoretical health education and health promotion and methodology researches in this field $[23,24,31]$. The questionnaire of this part includes (1) Assessment of level of knowledge with 15 questions (with yes and no options and score of 0 and 1), (2) Assessing the perceived susceptibility with 5 questions (in 5-point Likert scale option from totally disagree to completely agree, and score 0-4), (3) Assessing the perceived severity with 5 questions (in 5-point Likert scale from completely disagree to completely agree, and score $0-4$ ), (4) Assessing the level of perceived benefits with 6 questions (in 5-point Likert scale from completely disagree to strongly agree and score 0-4), (5) Assessing the level of perceived barriers with 6 questions (in 5-point Likert scale from completely disagree to strongly agree and score 0-4), (6) Assessing the level of subjective norms encouraging for Pap-smear test with 5 questions (in 5-point Likert scale from completely disagree to strongly agree and score 0-4), (7) Assessing the level of perceived behavior control with 2 questions (in 5-point Likert scale from very low to very high and score 1-5), (8) Assessing the level of behavior intention with 2 questions (in 5 -point Likert scale from very low to very high and score $1-5)$. The questionnaire developed for this study is provided as Additional file 1 . The validity and reliability of the tools used in cross-sectional studies, conducted on the target population (women admitted to health centers of Fasa) were confirmed. The content validity was evaluated through the impact index item higher than 0.15 and content validity ratio higher than 0.79 . For determining the face validity of tools, a list of arranged items was considered by 35 women with similar demographic, economic, and social characteristics with studied subjects. For determining content validity, the ideas of 12 specialists (out of the research team) in health education and promotion $(\mathrm{n}=10)$ and Gerontologist $(\mathrm{n}=2)$ were used. Based on Lawshe's table, items with a CVR value higher than 0.56 for 12 people were considered acceptable and retained for subsequent analysis. Also, in current research, the calculated values for most of the items were higher than 0.70 .

According to the calculated Cronbach's alpha, the total consistency of research tools was 0.88 . The consistency of knowledge was 0.86 , perceived susceptibility was 0.87 , perceived severity was 0.85 , perceived benefits was 0.88 , perceived barriers was 0.87 , perceived behavioral control was 0.82 , subjective norms was 0.87 and the behavioral intention was 0.86 .

The educational intervention was conducted by the research team after conducting the pilot studies. These pilot studies were carried out to evaluate the factors affecting the Pap smear test based on the health Belief model and theory of planned behavior in women supported by urban centers of Fasa $[26,30]$. The educational 
program focused on the mentioned structures and the considered educational content was prepared based on the educational manual and the educational PowerPoint and film display. The goal of the educational program was to enhance the knowledge of women on cervical cancer, familiarity with the potential risk factors and its complications and symptoms, perceiving the severity of the disease in the samples, and perceiving the benefits of the Pap smear test, identifying the barriers of screening, individual and social management of factors related to Pap smear test, and providing guidelines to prevent cervical cancer. The educational planning in this research was based on an active learning approach and the participants were actively involved in the educational program during the educational intervention and 4 experts of the department manage to control non-communicable diseases in the Fasa Health Center also contributed to the implementation of the program. The educational program for the experimental group was held in eight 50-min educational sessions, once per week in the form of group discussion, brainstorming, question and answer, film display (on mental Beliefs, the positive and negative outcomes of behavior, on the factors facilitating the behavior and the motivation to follow the influential people and the subjective norms), and PowerPoint in the conference hall of the Health Center of Fasa by using gynecologists and health education experts. A session was also held with the presence of spouses, physicians, and health center staff, and their role as supporters and subjective norms in conducting screening behaviors was emphasized. To change the perceived behavioral control on the factors facilitating the Pap smear test, group discussion was held, solutions to improve the willingness of people to do a Pap smear test were provided in each session. At the end of the educational sessions, an educational booklet and an educational CD were provided for them. At the end of educational sessions, an educational message concerning the importance of cervical cancer prevention and screening behaviors was sent to subjects each week and a telegram group was formed for the exchange of information and thoughts, and a followup session was held every month. Women were admitted to Fatemiyeh Clinic of Fasa to receive a Pap smear test. Six months after educational intervention, the questionnaire was completed by two experimental and control groups. After the research completion and to observe the research ethics, an educational session on cervical cancer and a Pap smear test was held for the control group. This research was approved in research design at Fasa University of Medical Sciences and an ethics code was received. Data were analyzed using SPSS 22 software, independent $t$-test, Chi-square, and paired $T$-test and the significance level was considered to be 0.05 .

\section{Results}

In this research, 300 women supported by Fasa health centers were examined. The mean age of the women in the experimental group and the control group was $32.18 \pm 7.34$ years and $33.47 \pm 7.13$ years, respectively, $(P=0.136)$. The mean of the first gestational age in the experimental group and the control group was $19.22 \pm 6.66$ and $19.98 \pm 6.59$, respectively, $(P=0.162)$. The mean number of children in the experimental group and the control group was $2.68 \pm 1.23$ and $2.77 \pm 1.34$, respectively, $(P=0.278)$. Independent $t$-test showed no significant difference between the two groups.

Chi-square test showed no significant difference between the experimental and control groups in terms of the variables of educational level $(P=0.264)$, job $(P=0.120)$, history of cervical cancer in the family $(P=0.153)$, history of receiving Pap smear test $(P=0.122)$ and being postmenopausal $(P=0.253)$ (Table 1$)$.

The results of this research revealed no significant difference between control and experimental groups in terms of the mean score of knowledge $(p=0.09)$, perceived susceptibility $(p=0.104)$, perceived severity $(p=0.135)$ and perceived benefits $(p=0.176)$, perceived barriers $(p=0.121)$, perceived behavioral control $(p=0.289)$, subjective norms $(p=0.332)$, and behavioral intention $(P=0.335)$, but significant difference was found between them 6 months after educational intervention

Table 1 Demographic characteristics of the subjects studied

\begin{tabular}{|c|c|c|c|c|c|}
\hline \multirow[t]{2}{*}{ Variable } & \multicolumn{2}{|c|}{$\begin{array}{l}\text { Experimental } \\
\text { group } \mathrm{N}=150\end{array}$} & \multicolumn{2}{|c|}{$\begin{array}{l}\text { Control } \\
\text { group } \\
\mathrm{N}=150\end{array}$} & \multirow[t]{2}{*}{$P$-value } \\
\hline & $\mathbf{n}$ & $\%$ & $\mathbf{n}$ & $\%$ & \\
\hline \multicolumn{6}{|l|}{ Education } \\
\hline Illiterate & 3 & 2 & 2 & 1.33 & 0.264 \\
\hline Elementary & 15 & 10 & 18 & 12 & \\
\hline Secondary school & 57 & 38 & 54 & 36 & \\
\hline High school & 62 & 41.33 & 60 & 40 & \\
\hline Academic & 13 & 8.67 & 16 & 10.67 & \\
\hline \multicolumn{6}{|l|}{ Job } \\
\hline Employed & 24 & 16 & 27 & 18 & 0.120 \\
\hline Housekeeper & 126 & 84 & 123 & 82 & \\
\hline \multicolumn{6}{|c|}{$\begin{array}{l}\text { History of cervical cancer in the } \\
\text { family }\end{array}$} \\
\hline Yes & 9 & 6 & 6 & 4 & 0.153 \\
\hline No & 141 & 94 & 144 & 96 & \\
\hline \multicolumn{6}{|c|}{ History of receiving Pap smear test } \\
\hline Yes & 58 & 38.67 & 62 & 41.33 & 0.122 \\
\hline No & 92 & 61.33 & 88 & 58.67 & \\
\hline \multicolumn{6}{|c|}{ Being postmenopausal } \\
\hline Yes & 12 & 8 & 14 & 9.33 & 0.253 \\
\hline No & 138 & 92 & 136 & 9.67 & \\
\hline
\end{tabular}


$(P<0.05)$. A paired $t$-test $(p=0.05)$ showed that the mean score of knowledge, perceived susceptibility, perceived severity, perceived benefits, perceived behavioral control, subjective norms, and behavioral intention were significantly increased in the experimental group and the mean score of perceived barriers decreased $(P<0.05)$. In the control group, the mean score of knowledge, perceived susceptibility, perceived severity, perceived benefits, perceived barriers, perceived behavioral control, subjective norms, and behavioral intention did not change significantly $(P>0.05)$ (Table 2$)$.

The results revealed that 6 months after the intervention, 108 women $(72 \%)$ in the experimental group and only 9 women $(6 \%)$ in the control group received the Pap smear test $(P<0.05)$.

\section{Discussion}

In cross-sectional research carried out on 700 women supported by health centers of Fasa city, $45.7 \%$ of the participants had a history of receiving Pap smear test, and
$20.7 \%$ of them received this test, and $6.86 \%$ of women had a history of cervical cancer in the family [30].

The results showed that the mean score of knowledge of women in experimental and control groups concerning cervical cancer and its prevention was at a low level, but 6 months after educational intervention, the mean score of knowledge in the experimental group showed a significant increase comparing to control group. The research carried by Donati et al. showed that Italian women who participated in the research had aged 18-26 years in 2008, had a low level of knowledge and false understanding of uterine cancer and its prevention. The subjects considered the health care providers as their most trusted source to receive the medical information [32]. As the population studied in this research included the women supported by health centers, providing educational programs by using educational theories such as theory of planned behavior and the health Belief model by the staff of these centers would be an important action to enhance the knowledge, attitude, and practice of women on the Pap smear test. In a research carried out

Table 2 Comparison of the mean scores of knowledge, perceived susceptibility, perceived severity, perceived benefits, perceived barriers, perceived behavioral control, subjective norms, and behavioral intention of the subjects before and 6 months after intervention in the experimental and control groups

\begin{tabular}{|c|c|c|c|c|}
\hline Variable & Group & Before intervention & $\begin{array}{l}6 \text { months after } \\
\text { intervention }\end{array}$ & Paired $t$-test \\
\hline \multirow[t]{3}{*}{ Knowledge } & Experimental & $6.55 \pm 2.09$ & $11.20 \pm 2.47$ & 0.001 \\
\hline & Control & $7.11 \pm 2.58$ & $7.26 \pm 2.66$ & 0.130 \\
\hline & Independent $t$ test & 0.09 & 0.001 & \\
\hline \multirow[t]{3}{*}{ Perceived susceptibility } & Experimental & $8.32 \pm 2.15$ & $15.11 \pm 2.64$ & 0.001 \\
\hline & Control & $8.40 \pm 2.86$ & $9.15 \pm 2.78$ & 0.148 \\
\hline & Independent $t$ test & 0.104 & 0.001 & \\
\hline \multirow[t]{3}{*}{ Perceived severity } & Experimental & $8.32 \pm 2.12$ & $16.14 \pm 2.16$ & 0.001 \\
\hline & Control & $7.97 \pm 2.86$ & $8.20 \pm 2.91$ & 0.172 \\
\hline & Independent $t$ test & 0.135 & 0.001 & \\
\hline \multirow[t]{3}{*}{ Perceived benefits } & Experimental & $8.70 \pm 2.43$ & $18.26 \pm 2.71$ & 0.001 \\
\hline & Control & $9.04 \pm 2.36$ & $10.12 \pm 2.22$ & 0.198 \\
\hline & Independent $t$ test & 0.176 & 0.001 & \\
\hline \multirow[t]{3}{*}{ Perceived barriers } & Experimental & $18.16 \pm 2.52$ & $7.26 \pm 2.57$ & 0.001 \\
\hline & Control & $18.78 \pm 2.35$ & $17.46 \pm 2.41$ & 0.256 \\
\hline & Independent $t$ test & 0.121 & 0.001 & \\
\hline \multirow[t]{3}{*}{ Behavioral control } & Experimental & $4.13 \pm 1.08$ & $8.34 \pm 1.09$ & 0.001 \\
\hline & Control & $4.25 \pm 1.10$ & $5.68 \pm 1.13$ & 0.412 \\
\hline & Independent $t$ test & 0.289 & 0.001 & \\
\hline \multirow[t]{3}{*}{ Subjective norms } & Experimental & $8.12 \pm 2.42$ & $16.19 \pm 2.28$ & 0.001 \\
\hline & Control & $7.90 \pm 2.75$ & $8.14 \pm 2.76$ & 0.166 \\
\hline & Independent $t$ test & 0.322 & 0.001 & \\
\hline \multirow[t]{3}{*}{ Behavioral intention } & Experimental & $4.06 \pm 0.79$ & $8.38 \pm 1.13$ & 0.001 \\
\hline & Control & $4.14 \pm 0.97$ & $4.27 \pm 1.11$ & 0.528 \\
\hline & Independent $t$ test & 0.355 & 0.001 & \\
\hline
\end{tabular}


by Sha-mohammadi et al., they investigated the factors affecting the doing the Pap smear test based on a combination of the theory of planned behavior and the stages of behavior change. The model structures predicted 31\% of the behavioral intention variance, and most people were in the pre-thinking stage [33]. In a research carried out by Hazavehei et al. on 124 women in Khomeinishahr city, educational intervention based on the health Belief model increased the knowledge score of women in the experimental group after the educational intervention [34]. In qualitative research carried out by Keshavarz et al. using a combination of theory of planned behavior and self-efficacy on 70 women aged $20-45$ years, it was found that the knowledge level and attitude of women toward breast and cervical cancer screening methods were at a low level [35]. The results of studies conducted by Park Somi et al. [36], Twinn et al. [37], Karimy et al. [38], Yakhforoushha et al. [39], and Arshad et al. [40] are in line with those of this research.

The research results showed that the mean score of perceived susceptibility and perceived severity of both groups were low before the research, indicating that women of both groups did not consider themselves at risk for cervical cancer, while in the research conducted on women in Botswana, most of the women considered themselves at risk for cervical cancer [41]. Six months after the educational intervention, the mean score of perceived susceptibility in the experimental group was significantly higher compared to that in the control group. Health educators require taking action to develop perceived susceptibility and perceived severity by describing the probability of incidence of negative outcomes and exposing the risks for the clients. In research carried out by Bahmani et al. on 180 women, the educational intervention increased the mean score of perceived susceptibility in the experimental group, but the mean score of perceived severity did not change [42]. In cross-sectional research carried out by Jeihooni et al., the structures of perceived susceptibility and perceived benefits were the most important predictors of the Pap smear test [26]. In the research carried out by Jowzi et al., no significant relationship was found between doing Pap smear test, perceived vulnerability, and perceived severity [43]. In research, Khademolhosseini et al. evaluated the effect of educational intervention based on the health Belief model through the telegram message on Pap smear performance of women. It was found that knowledge level, susceptibility, and perceived severity of people increased 3 months after the intervention [44]. The results of other studies are also in line with those of this research $[34,39$, 45-49].

The research results revealed no difference between the experimental and control groups concerning perceived benefits and perceived barriers before the educational intervention, but educational intervention increased the mean score of perceived benefits and reduced the mean score of perceived barriers in the experimental group, while no significant difference was observed in the control group. In analyzing the behavior of women on Pap smear, a significant relationship was found between the perceived benefits and reduced barriers and performance based on the health Belief model [27]. In this research, education based on the health Belief model resulted in a better perception of the benefits by the experimental group and overcome the barriers more effectively. In their research, McFarland et al. reported that women who had more barriers received less Pap smear over the last 5 years [41]. In the research carried out by Somi Park et al. a significant difference was found between the experimental and control groups after the intervention in cognitive barriers and barriers related to doing the Pap smear. They justified this difference as the effect of educational intervention and providing information on cervical cancer and discussion on the value of Pap smear in educational sessions [36]. In cross-sectional research carried out by Jeihooni et al., the level of susceptibility, severity, perceived benefits, and perceived barriers in subjects who had a history of Pap smear test were higher compared to those who did not have this test. The most common reason for the test was health care staff guidelines, and the most important reason for the non-test was the Belief that they are not prone to cervical cancer [26]. The results of the research carried by Rakhshani et al. [50], Karimy et al. [38], Bahmani et al. [42], and Park et al. [36] are in line with the results of the current research. The mean score of perceived behavioral control in the experimental group was significantly higher than that in the control group 6 months after the intervention. Education on cervical cancer and doing a Pap smear test through educational sessions and providing appropriate incentive and informational feedback in group discussions improved the perceived behavioral control in the experimental group. Perceived behavior control and the feeling that behavior is voluntary is one of the important factors in taking step to perform that behavior [51], and increasing perceived behavioral control following educational intervention indicates the impact of education in developing this perception that "if I want, I can do Pap smear test". The research carried out by Roncancio et al. revealed that perceived behavioral control and subjective norms are positively correlated with the intention for cervical cancer screening [52]. In the research carried out by Linton, perceived behavioral control showed direct effect on Pap-smear behavior [53].

In the research carried out by Ogilvie et al. perceived behavioral control and subjective norms predicted 
cervical cancer screening [54]. In the research conducted by Teitelman et al. the perceived behavioral control and subjective norms predicted the intention for Pap smear test [55]. In cross-sectional study research carried out on married women admitted to health centers in Fasa, a significant relationship was found between knowledge, abstract norm, and perceived behavioral control and screening behavior [30]. Consistent with findings of the current research, Sweeney et al. [56], Sha-Mohammadi et al. [33], the educational intervention increased the mean score of perceived behavioral control in the experimental group. The current research findings revealed that the mean score of subjective norms in the experimental group was significantly higher than that in the control group 6 months after the intervention. The subjective norms are among theory of planned behavior structures, referring to effective social pressures for adopting the considered behavior. When the social pressures and supports of the family members, especially spouses, physicians, health care staff, and friends to perform health behaviors by an individual are high, adopting that behavior by that individual would be also high [57]. In the research conducted by Keshavarz et al. decreased level of subjective norms especially support of partner and low knowledge was reported as negative factors for cervical cancer screening [58]. In research carried out on Taiwanese women, subjective norms predicted cervical cancer screening [59]. In research conducted by Jalilian et al., the most important predictor for Pap smear test was found to be subjective norms. In this research, spouse, physician, and educational programs were found to be influential factors [29]. In research carried out on 206 women aged 18-26 years in Singapore, Chrayil et al. found that subjective norms were the most important predictors of the Pap test, and perceived behavior control had the moderate predictive power [60]. The research carried out by Silva et al. revealed that social support had a positive effect on the Pap smear test [61]. In the research conducted by Karimy et al. the most important guide to Pap test was health staff [38]. The results of other studies are consistent with those of the current research [38, 62-64].

This research results revealed that the mean score of behavioral intention in the experimental group increased during the 6 months after the intervention, while no change was seen in the control group. Six months after the intervention, $72 \%$ of the experimental group subjects and $6 \%$ of control group subjects received the Pap smear, indicating the effect of educational intervention on the Pap test in the experimental group. The intention is the most important structure in this regard so that by changing this structure, more adoption of the selfcare behaviors can be expected from people [30]. In the research carried out by Moradi et al. theory of planned behavior predicted $57.4 \%$ of the intention variance and $31.6 \%$ of Pap smear screening test variance [30]. In the research carried out by Roncancio et al. variance value was $27.6 \%$ for intention and $13 \%$ for cervix screening [52]. In a research carried out by McClenahan et al. they used a combination of the health Belief model and theory of planned behavior for testicular self-Examination (TSE). The theory of planned behavior predicted $50 \%$ of intention variance and $22 \%$ of behavior variance and the health Belief model predicted $56 \%$ of intention variance and $21 \%$ of behavior variance [65].

In the research carried out by Sha-Mohammadi et al. [33], the educational intervention increased the mean score of intention and screening behaviors in the experimental group subjects. In other studies, it was found that educational intervention resulted in Pap smear test screening [42, 44, 46, 66].

The limitations of the present study included the use of self-report method for data collection which limit the generalizability of the results. Regardless of these limitations, this study has some advantages. This study was the direct education approach in educational strategy which the result of our study along with other studies showed advantages of using this strategy compare to other different health education approaches and methods (such as calls, mailed postcards...) $[67,68]$.

\section{Conclusion}

The current research results revealed that education based on the combination of the health Belief model and theory of planned behavior might be promoting participation and an increasing rate of receiving Pap smear tests in women. The reason for the effectiveness of the program used in this research is recognizing the weaknesses before the intervention and developing educational strategies and content based on them. This research results suggest that when women gain adequate knowledge on cervical cancer and Pap smear test, see themselves as prone to it, take its risk seriously, obtain the high perception of behavioral control to do Pap smear test, feel fewer barriers to perform the behavior, and subjective norms such as support of family member and health care staff cooperate, the intention and performing the behavior in women would also enhance.

Therefore, Well-planned, comprehensive and integrated approach, based on clients' needs and requirements, is the most important characteristic of a successful screening program. It should include health education and health promotion elements, and interventions of the health care staff need to be based on these principles. Also, comprehensive educational programs through mass media such as TV and newspapers would be helpful in this regard. Similar studies are required to use other behavior change models 
for regular and continuous evaluation of behavior change at longer intervals (more than 6 months).

\author{
Abbreviations \\ HBM: Health Belief Model; TPB: Theory of Planned Behavior.
}

\section{Supplementary Information}

The online version contains supplementary material available at https://doi. org/10.1186/s12905-021-01419-w.

Additional file 1. The questionnaire of this study.

\section{Acknowledgements}

The researchers would like to appreciate the staff of Health Centers and all the women who participated in this study.

\section{Authors' contributions}

$\mathrm{AKHJ}$ and $\mathrm{HJ}$ assisted in the conceptualization and design of the study, oversaw data collection, conducted data analysis, and drafted the manuscript. PAH conceptualized and designed the study, assisted in data analysis, and reviewed the manuscript. AKHJ, HJ, and PAH assisted in study conceptualization and reviewed the manuscript. All authors read and approved the final manuscript.

\section{Funding}

This study was funded by the Fasa University of Medical Sciences that participated in the financial support of this study. However, this funding source had no role in the analysis and interpretation of data, in the writing of the article, nor in the decision to submit it for publication.

\section{Availability of data and materials}

All supporting data are available through the corresponding author.

\section{Declarations}

\section{Ethical approval and consent to participate}

All the women were informed about the quality of the project's implementation, confidentiality of the information, and the project's purpose. They were not enrolled in the study unless they would like. Participants indicated their informed consent by clicking the "I Agree" button before completing the questionnaire. According to the guidelines of the Iranian ethics committee, the participants were considered emancipated minors. Thus, written informed consent was received from them and the care centers' manager. The Ethics Committee approved this study with all consent process at Fasa University of Medical Sciences.

\section{Consent to publish}

Not applicable.

\section{Competing interests}

The authors declare that they have no competing interests.

\section{Author details}

${ }^{1}$ Nutrition Research Center, Department of Public Health, School of Health, Shiraz University of Medical Sciences, Shiraz, Iran. ${ }^{2}$ Department of Health Education and Promotion, School of Health, Hamadan University of Medical Sciences, Hamadan, Iran. ${ }^{3}$ Department of Public Health, School of Health, Kermanshah University of Medical Sciences, Kermanshah, Iran.

Received: 16 November 2020 Accepted: 6 July 2021

Published online: 06 August 2021

\section{References}

1. Daniyal M, Akhtar N, Ahmad S, Fatima U, Akram M, Asif HM. Update knowledge on cervical cancer incidence and prevalence in Asia. Asian Pac J Cancer Prev. 2015;16(9):3617-20

2. Bray F, Ferlay J, Soerjomataram I, Siegel RL, Torre LA, Jemal A. Global cancer statistics 2018: GLOBOCAN estimates of incidence and mortality worldwide for 36 cancers in 185 countries. CA Cancer J Clin. 2018;68(6):394-424.

3. Ginsburg O, Bray F, Coleman MP, Vanderpuye V, Eniu A, Kotha SR, et al. The global burden of women's cancers: a grand challenge in global health. The Lancet. 2017;389(10071):847-60.

4. Momenimovahed Z, Salehiniya H. Cervical cancer in Iran: integrative insights of epidemiological analysis. BioMedicine. 2018;8(3):18.

5. Arbyn M, Weiderpass E, Bruni L, de Sanjosé S, Saraiya M, Ferlay J, et al. Estimates of incidence and mortality of cervical cancer in 2018: a worldwide analysis. Lancet Glob Health. 2020;8(2):e191-203.

6. Aggarwal P. Cervical cancer: can it be prevented? World J Clin Oncol. 2014;5(4):775.

7. Guvenc G, Akyuz A, Açikel CH. Health belief model scale for cervical cancer and Pap smear test: psychometric testing. J Adv Nurs. 2011;67(2):428-37.

8. Hadi N, Azimirad A. Knowledge attitude and practice of women in shiraz about cervical cancer and pap smear 2009. Iran J Cancer Prev. 2010;3(3):117-26.

9. Malmir S, Barati M, Khani Jeihooni A, Bashirian S, Hazavehei SMM. Effect of an educational intervention based on protection motivation theory on preventing cervical cancer among marginalized women in West Iran. Asian Pac J Cancer Prev. 2018;19(3):755-61.

10. Bashirian S, Barati M, Mohammadi Y, MoaddabShoar L, Dogonchi M. Evaluation of an intervention program for promoting breast self-examination behavior in employed women in Iran. Breast Cancer Basic Clin Res. 2021;15:1178223421989657.

11. Small W Jr, Bacon MA, Bajaj A, Chuang LT, Fisher BJ, Harkenrider MM, et al. Cervical cancer: a global health crisis. Cancer. 2017;123(13):2404-12.

12. Bakhtari Aghdam F, Nouri Zadeh R, Sahebi L. Effect of education based on health belief model and develop behaviors that promote breast cancer screening in women referring to Tabriz health centers. Tabriz Univ Med Sci J. 2012;33(6):25-31.

13. Mukherjee K, Saraf DS, Bose V, Grover A, Chahar A, Godinho MA, et al. Effectiveness and cost-effectiveness of population-based cervical cancer screening in LMICs: a systematic review. Campbell Collab. 2017. https:// www.campbellcollaboration.org/media/k2/attachments/IDCG_Mukhe rjee_Title.pdf.

14. Coughlin SS, King J, Richards TB, Ekwueme DU. Cervical cancer screening among women in metropolitan areas of the United States by individuallevel and area-based measures of socioeconomic status, 2000 to 2002. Cancer Epidemiol Prev Biomark. 2006;15(11):2154-9.

15. Fylan F. Screening for cervical cancer: a review of women's attitudes, knowledge, and behaviour. Br J Gen Pract. 1998;48(433):1509-14.

16. Waller J, Bartoszek M, Marlow L, Wardle J. Barriers to cervical cancer screening attendance in England: a population-based survey. J Med Screen. 2009;16(4):199-204.

17. Basu P, Mittal S, Bhadra Vale D, Chami KY. Secondary prevention of cervical cancer. Best Pract Res Clin Obstet Gynaecol. 2018;47:73-85.

18. Farzaneh $E$, Heydari H, Shekarchi AA, Kamran A. Breast and cervical cancer-screening uptake among females in Ardabil, northwest Iran: a community-based study. Onco Targets Ther. 2017;10:985-92.

19. Majdfar Z, Khodadost M, Majlesi F, Rahimi A, Shams M, Mohammadi G. Relationships between self-efficacy and pap smear screening in Iranian women. Asian Pac J Cancer Prev. 2016;17(S3):263-8.

20. Addis IB, Hatch KD, Berek JS. Intraepithelial disease of the cervix vagina and vulva. In: Berek JS, editor. Berek \& Novak's gynecology. Philadelphia: Lippincott Williams \& Wilkins; 2002.

21. Karimy M, Shamsi M, Araban M, Gholamnia Z, Kasmai P. Pap smear test structures for measuring health belief model and factors affecting women in urban centers covered Zarandieh. Qom Univ Med Sci J. 2012;6(3):52-9.

22. Cohen D, Austin RM, Gilbert C, Freij R, Zhao C. Follow-up outcomes in a large cohort of patients with human papillomavirus-negative ASC-H cervical screening test results. Am J Clin Pathol. 2012;138(4):517-23. 
23. Glanz K, Rimer BK, Viswanath K. Health behavior and health education: theory, research, and practice. Hoboken: Wiley; 2008.

24. Sharma M. Theoretical foundations of health education and health promotion. Burlington: Jones \& Bartlett Publishers; 2016.

25. Jeihooni AKHA, Kaveh MH, Hajizadeh E, Askari A. The effect of an educational program based on health belief model on preventing osteoporosis in women. Int J Prev Med. 2015;6:115.

26. Khani Jeihooni A, Kashfi SM, Bahmandost M, Kashfi SH. The survey of factors affecting pap smears based on health belief model in health centers in fasa, Fars province, Iran. Women's Health Bulletin. 2015;2(4):1-6.

27. Allahverdipour H, Emami A. Perceptions of cervical cancer threat, benefits, and barriers of papanicolaou smear screening programs for women in Iran. Women Health. 2008:47(3):23-37.

28. Jalilian FMAM, Emdadi S, Barati M, Nasirzadeh M, Hatamzadeh N. Predicting factors related with Pap smear testing among women based on health belief model. J Health Syst Res. 2012;7(6):1226-35.

29. Jalilian F, Emdadi S. Factors related to regular undergoing pap-smear test: application of theory of planned behavior. J Res Health Sci. 2011;11(2):103-8.

30. Moradi Z, Moradi P, Khani Jeihooni A, Dehghan A. Factors associated with Pap smear implementation among women referring to healthcare centers in Fasa, Iran: an application of theory of planned behavior. J Educ Community Health. 2017;4(1):51-8.

31. Kumar S, Phrommathed P. Research methodology. Berlin: Springer; 2005. p. 43-50.

32. Donati S, Giambi C, Declich S, Salmaso S, Filia A, degli Atti ML, et al. Knowledge, attitude and practice in primary and secondary cervical cancer prevention among young adult Italian women. Vaccine. 2012;30(12):2075-82.

33. Sha-Mohammadi Z, Jalilian F, Mirzaei-Alavijeh M, Mahboubi M, ZinatMotlagh F, Karami-Matin B, et al. Intention and behavioral stages in pap testing: a cross-sectional study among kermanshah women's, the west of Iran. J Biol Today's World. 2014;3(1):11-4.

34. Hazavehei SM, Rahmati M, Hasanzade A. Effect of educational program based on health belief model on the practice of women about pap smear. J Health Syst Res. 2014;9:1858-67.

35. Keshavarz Z, Simbar M, Ramezankhani A, Alavi MH. Factors influencing the behavior of female-workers in the reproductive age regarding breast and cervical cancer screening based on the integrated model of planned behavior and self-efficacy: a qualitative approach. J School Public Health Inst Public Health Res. 2012;9(3):23-36.

36. Park S, Chang S, Chung C. Effects of a cognition-emotion focused program to increase public participation in Papanicolaou smear screening. Public Health Nurs. 2005;22(4):289-98.

37. Twinn S, Holroyd E, Fabrizio C, Moore A, Dickinson J. Increasing knowledge about and uptake of cervical cancer screening in Hong Kong Chinese women over 40 years. Hong Kong Med J. 2007;13(Suppl 2):S16-20.

38. Karimy M, Gallali M, Niknami S, Aminshokravi F, Tavafian S. The effect of health education program based on Health Belief Model on the performance of Pap smear test among women referring to health care centers in Zarandieh. J Jahrom Univ Med Sci. 2012;10(1):53-9.

39. Yakhforushha A, Solhi M, Azar FEF. Effects of education via health belief model on knowledge and attitude of voluntary health workers regarding Pap smear in urban centers of Qazvin. Adv Nurs Midwifery. 2008;18(63):27-33.

40. Arshad SM, Khani-jeihooni A, Moradi Z, Kouhpayeh SA, Kashfi SM, Dehghan A. Effect of theory of planned behavior-based educational intervention on breastfeeding behavior in pregnant women in Fasa city. Iran J Educ Community Health. 2017;4(2):55-63.

41. McFarland DM. Cervical cancer and Pap smear screening in Botswana: knowledge and perceptions. Int Nurs Rev. 2003;50(3):167-75.

42. Bahmani A, Gharib A, Rahmani K, Ahmadian F, Alizadeh Z, Akhtar B. Effect of health belief model education on the participation of rural women in papsmear test. J Nurs Educ. 2016;4(5):34-40.

43. Jowzi F, Hashemifard T, Morowatisharifabad M, Bashir Z. Factors associated with pap smear screening test among women aged 15-49 based on protection motivation theory. Hayat. 2013;19(1):29-40.

44. Khademolhosseini F, Noroozi A, Tahmasebi R. The effect of health belief model-based education through telegram instant messaging services on Pap smear performance. Asian Pac J Cancer Prev APJCP. 2017;18(8):2221.

45. Leyva M, Byrd T, Tarwater P. Attitudes towards cervical cancer screening. Calif J Health Promot. 2006;4(2):13-24.

46. Pirzadeh $\mathrm{A}$. The effect of health education based on health belief model on performance of women regarding Pap smear test in Kouhdasht health centers in 2010. J Health Syst Res. 2011;6(2):365-72.

47. Jeihooni AK, Askari A, Kashfi SM, Khiyali Z, Kashfi SH, Safari O, et al. Application of health belief model in prevention of osteoporosis among primary school girl students. Int J Pediatr Mashhad. 2017;5(11):6017-29.

48. Jeihooni AK, Kashfi SM, Shokri A, Kashfi SH, Karimi S. Investigating factors associated with FOBT screening for colorectal cancer based on the components of health belief model and social support. Asian Pac J Cancer Prev APJCP. 2017;18(8):2163.

49. Kashfi S, Jeihooni AK, Rezaianzadeh A, Amini S. The effect of health belief model educational program and jogging on control of sugar in type 2 diabetic patients. Iran Red Crescent Med J. 2012;14(7):442.

50. Rakhshani F, Jalilian F, Mirzaei Alavijeh M, Zinat Motlagh F, Aghaei A, Ahmadi-Jouibari T. Pap smear test among women: an educational intervention based on health belief model. J Birjand Univ Med Sci. 2013;20(2):136-43.

51. Ahmadi M, Jahanara S, Moeini B, Nasiri M. Impact of educational program based on the theory of planned behavior on primiparous pregnant women's knowledge and behaviors regarding breast feeding. J Health Care. 2014;16(1):19-31.

52. Roncancio AM, Ward KK, Sanchez IA, Cano MA, Byrd TL, Vernon SW, et al. Using the theory of planned behavior to understand cervical cancer screening among Latinas. Health Educ Behav. 2015;42(5):621-6.

53. Linton D. Pap smear intention among rural southeast Louisiana women. [PhD Dissertation]. Louisiana: Louisiana State University Health Sciences Center School of Nursing; 2009.

54. Ogilvie GS, Smith LW, van Niekerk DJ, Khurshed F, Krajden M, Saraiya $M$, et al. Women's intentions to receive cervical cancer screening with primary human papillomavirus testing. Int J Cancer. 2013;133(12):2934-43.

55. Teitelman AM, Stringer M, Nguyen GT, Hanlon AL, Averbuch T, Stimpfel AW. Social cognitive and clinical factors associated with HPV vaccine initiation among urban, economically disadvantaged women. J Obstet Gynecol Neonatal Nurs. 2011;40(6):691-701.

56. Sweeney JB, MCAnulty RD, Reeve C, Cann A. An intervention for HPV risk reduction based on the theory of planned behavior: an exploratory study with college-aged women. Am J Sex Educ. 2015;10(3):199-217.

57. Dydarlu A. Effect of educational intervention based on the theory of developed reasoned action to promote of self-management in women with type 2 diabetes. Tehran: Tehran University of Medical Sciences; 2011.

58. Keshavarz Z, Simbar M, Ramezankhani A, Alavi Majd H. Factors influencing the behavior of female-workers in the reproductive age regarding breast and cervical cancer screening based on the integrated model of planned behavior and self-efficacy: a qualitative approach. J School Public Health Inst Public Health Res. 2012;9(3):23-36.

59. Lu H-Y. Determinants of intentions among Taiwanese women to seek information regarding cervical cancer. J Nurs Res. 2014;22(2):101-10.

60. Chirayil El, Thompson CL, Burney S. Predicting human papilloma virus vaccination and pap smear screening intentions among young Singaporean women using the theory of planned behavior. SAGE Open. 2014;4(4):2158244014554961.

61. Gamarra CJ, Paz EPA, Griep RH. Social support and cervical and breast cancer screening in Argentinean women from a rural population. Public Health Nurs. 2009;26(3):269-76.

62. Kashfi SM, Jeihooni AK, Rezaianzadeh A, Karimi S. The effect of mothers education program based on the precede model on the mean weight in children (6-12 months) at health centers in Shiraz, Fars Province. Med J Islam Repub Iran. 2014;28:95.

63. Kashfi SM, Khani Jeihooni A, Rezaeianzade A. Effect of health workers' training programs on preventive behavior of leishmaniosis based on BASNEF model. J Res Health Sci. 2012:12(2):114-8.

64. Jeihooni AK, Kashfi SM, Kooshkghazi SZ, Kashfi SH. Effectiveness of a training program based in PRECEDE model on fruit and vegetable consumption among female students. Int J Pediatr. 2017;5:5935-44. 
65. McClenahan C, Shevlin M, Adamson G, Bennett C, O'Neill B. Testicular self-examination: a test of the health belief model and the theory of planned behaviour. Health Educ Res. 2007;22(2):272-84

66. Wanyoro A, Kabiru E, Bubusi E. Cervical cancer screening adherence and the SMS: Screening adherence and availability of the mobile phone SMS in women attending the outpatient clinic at Thika Level 5 Hospital. East Cent Africa Med J. 2015;2:3-6.

67. Saei Ghare Naz M, Kariman N, Ebadi A, Ozgoli G, Ghasemi V, Rashidi Fakari F. Educational interventions for cervical cancer screening behavior of women: a systematic review. Asian Pac J Cancer Prev. 2018;19(4):875-84
68. Rashid RMA, Mohamed M, Hamid ZA, Dahlui M. Is the phone call the most effective method for recall in cervical cancer screening?results from a randomised control trial. Asian Pac J Cancer Prev. 2013;14(10):5901-4.

\section{Publisher's Note}

Springer Nature remains neutral with regard to jurisdictional claims in published maps and institutional affiliations.
Ready to submit your research? Choose BMC and benefit from:

- fast, convenient online submission

- thorough peer review by experienced researchers in your field

- rapid publication on acceptance

- support for research data, including large and complex data types

- gold Open Access which fosters wider collaboration and increased citations

- maximum visibility for your research: over $100 \mathrm{M}$ website views per year

At BMC, research is always in progress.

Learn more biomedcentral.com/submissions 